\title{
Cryogenic Boil-Off Reduction System Testing
}

\author{
D.W. Plachta ${ }^{1}$ and W.L. Johnson ${ }^{2}$ \\ NASA Glenn Research Center, Cleveland, OH 44135 \\ J.R. Feller ${ }^{3}$ \\ NASA Ames Research Center, Moffett Field, CA 94035
}

\begin{abstract}
Cryogenic propellants such as liquid hydrogen $\left(\mathrm{LH}_{2}\right)$ and liquid oxygen $\left(\mathrm{LO}_{2}\right)$ are a part of NASA's future space exploration due to the high specific impulse that can be achieved using engines suitable for moving 10's to 100's of metric tons of payload mass to destinations outside of low earth orbit. However, the low storage temperatures of $\mathrm{LH}_{2}$ and $\mathrm{LO}_{2}$ cause substantial boil-off losses for missions with durations greater than several days. The losses can be greatly reduced by incorporating high performance cryocooler technology to intercept heat load to the propellant tanks and by the integration of self-supporting multi-layer insulation. The active thermal control technology under development is the integration of the reverse turboBrayton cycle cryocooler to the propellant tank through a distributed cooling network of tubes coupled to a shield in the tank insulation and to the tank wall itself. Also, the self-supporting insulation technology was utilized under the shield to obtain needed tank applied $\mathrm{LH}_{2}$ performance. These elements were recently tested at NASA Glenn Research Center in a series of three tests, two that reduced $\mathrm{LH}_{2}$ boil-off and one to eliminate $\mathrm{LO}_{2}$ boil-off. This test series was conducted in a vacuum chamber that replicated the vacuum of space and the temperatures of low Earth orbit. The test results show that LH2 boil-off was reduced $60 \%$ by the cryocooler system operating at $90 \mathrm{~K}$ and that robust LO2 zero boil-off storage, including full tank pressure control was achieved.
\end{abstract}

\section{Introduction}

S part of the U.S. National Space Policy, NASA is seeking an innovative path for space exploration, which

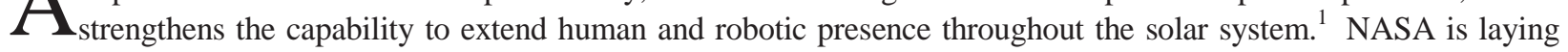
the groundwork to enable humans to safely reach multiple potential destinations. Mission architecture studies have consistently identified the need for in-space propulsion stages using high performance $\mathrm{LH}_{2}$ and $\mathrm{LO}_{2}$ as the propellant combination to enable more efficient crewed exploration. ${ }^{2-4}$ In addition, some mission architecture studies include consideration of options for propellant resupply, either via tankers or in-space propellant depots. ${ }^{5-7}$ These various mission capability elements have dictated the need to develop technology to improve the mass efficiency of longduration storage of cryogenic fluids. A driving factor in this efficiency is the high boil-off rates of $\mathrm{LH}_{2}$ and $\mathrm{LO}_{2}$, particularly in low Earth orbit (LEO) environment, due to the Earth's albedo and solar heating.

The greatest cryogenic technology challenge going forward is $\mathrm{LH}_{2}$ storage, due to its extremely low boiling point which makes it more challenging to achieve zero boil-off cryogenic storage. Active cooling concepts applied at $\mathrm{LH}_{2}$ temperatures are inherently inefficient due to the large temperature difference between the cold point and the heat rejection point, creating a maximum Carnot efficiency of $7 \%$. Unfortunately, the size of available flight coolers at $20 \mathrm{~K}$ is not large enough for propellant storage. This test series was focused on the much more available and higher capacity 90K cryocooler technology with its Carnot efficiency of $43 \%$, using a broad area cooling tube network to cool a shield coupled to the $\mathrm{LH}_{2}$ tank. The addition of cryocoolers as part of cryogenic boil-off reduction has been considered and tested at NASA and elsewhere. ${ }^{8,9}$ The shield is installed within the layers of insulation, effectively cooling them and reducing the hot side temperature of the insulation below the shield. Such a shield offers a hot side temperature for the $\mathrm{LH}_{2}$ tank of $90 \mathrm{~K}$, instead of the low earth orbit imposed temperature of roughly 220K. Coupled to this shield are straps and collars to cool the plumbing and tank supports. This concept, shown

\footnotetext{
${ }^{1}$ Cryogenics Engineer, Code LTF, M/S: 301-3

${ }^{2}$ Cryogenic Engineer, Fluid Test and Technology Branch, M/S: NE-F6, AIAA Senior Member.

${ }^{3}$ Researcher, Cryogenics Laboratory, M/S: 244-10.
} 
schematically in Figure 1, is projected to reduce the heat flux into the $\mathrm{LH}_{2}$ tank substantially and efficiently over large surface areas. Besides shield cooling for $\mathrm{LH}_{2}$ storage, a tube-on-tank cooling network was also tested for $\mathrm{LO}_{2}$ zero boil-off (ZBO) storage. This tubing network was installed on the tank under the MLI and worked with the same cryocooler system as the tube-on-shield concept. The operational difference was significant, however, as this network was used to directly control tank pressure.

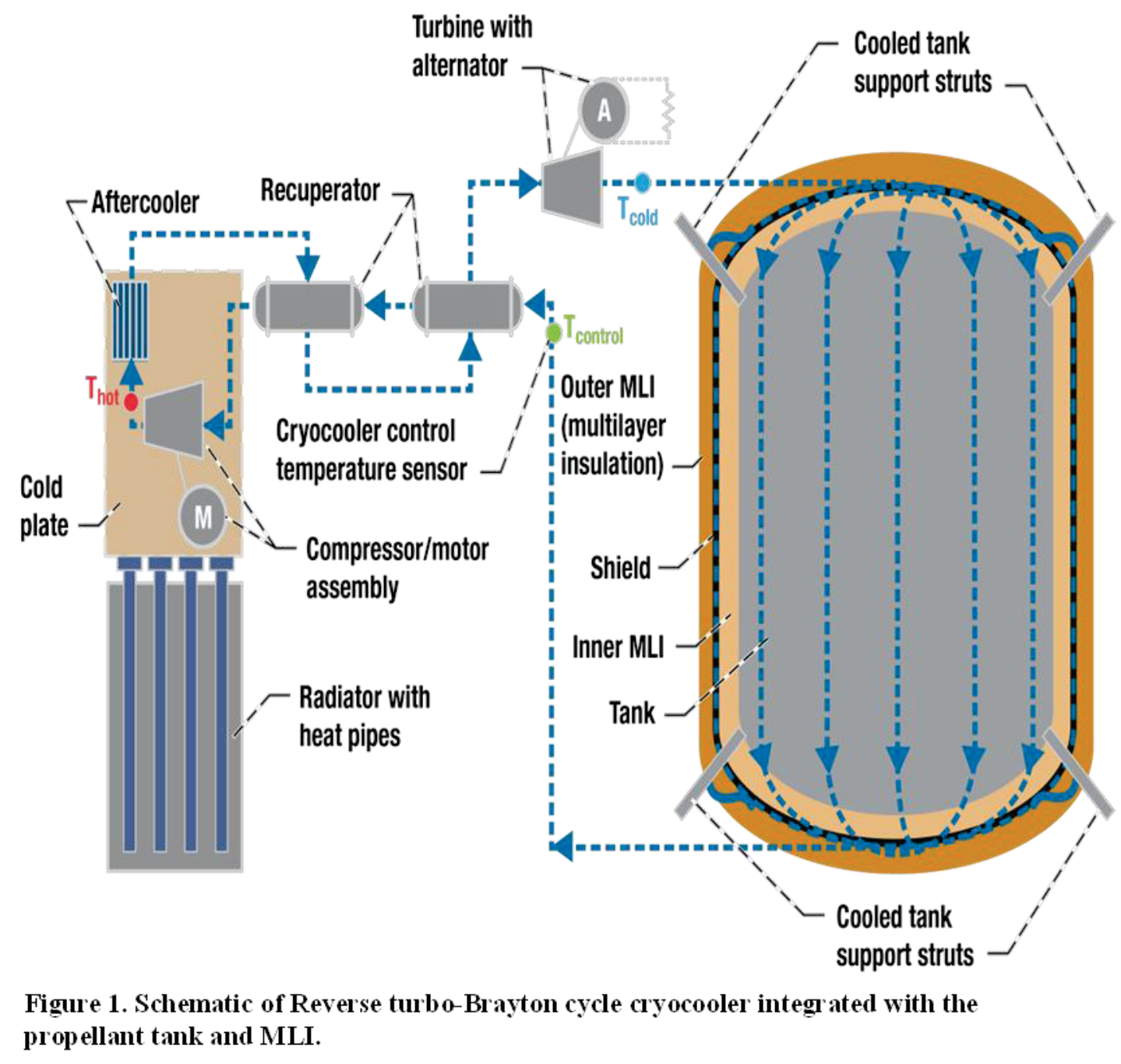

The cryocooler technology used in this cooling network is the reverse turbo-Brayton cycle cryocooler, which has the advantage of utilizing the cryocooler working fluid to continuously circulate the environmental heat leak away from the propellant tank. Compared to previous efforts that considered the integration of circulators with pulse-tube cryocoolers, this technology eliminates the counter-flow heat exchanger and its associated loss while having relatively high flow rates. Another advantage is that the reverse turbo-Brayton cycle cooler's efficiency improves ${ }^{10}$ with compressor pressure ratio, which is needed with higher capacities inherent with larger propellant tank sizes. These technology attributes were featured in the testing with $\mathrm{LH}_{2}$ and $\mathrm{LO}_{2}$ (using liquid nitrogen $\left(\mathrm{LN}_{2}\right.$ ) as a surrogate) propellants in a simulated LEO environment.

In addition to NASA's focus on the technology of efficiently integrating cryocoolers to propellant tanks, self-supporting multi-layer insulation ${ }^{11}$ (SS-MLI) technology was included in this developmental test. SS-MLI was initially developed through the NASA's Small Business Innovative Research program. It has lower layer density and a more defined structure and straightforward assembly than traditional MLI. It also offers the potential to support the broad area cooled shield and outer MLI with minimal heat addition to the propellant tank. The structural 
capabilities of the SS-MLI were addressed in vibro-acoustic testing at MSFC, ${ }^{12}$ which was successful. An equivalent structural design does not exist for traditional MLI, which is typically made from loosely sewn or pinned blankets, constructed differently at different vendors.

\section{Test Objectives}

The objectives in this test series were to determine the integrated system performance of a Cryogenic BoilOff Reduction System (CBRS) with a propellant tank, validate the existing scaling study model, ${ }^{13}$ advance the technology of reduced and zero boil-off concepts, prove the viability of self-supporting MLI, and to robustly achieve ZBO by controlling tank pressure with the cryocooler system. The integrated performance goal necessitated performing an end-to-end test with the cooling system, the propellant tank, and the heat rejection system all incorporated together within the vacuum chamber. The performance areas of interest included the flow loss, as the pressure drop must be overcome by the cryocooler compressor, the heat transfer in the cooling loop, and the unusable lift or parasitics of our cooling system integrated to the propellant tank. Thermal effectiveness in the cooling straps, used to couple the tank fluid lines and the tank struts thermally to the cooling shield, was also measured. Validation of the scaling study model was needed to confirm the study results, which project that the overall propellant storage concept demonstrated in CBRS begins to reduce total storage system mass after loiter periods of just a few weeks in low Earth orbit. The overall performance was of primary interest; specifically, the cryocooler lift and input power at the corresponding tank heat leak and the resultant system coefficient of performance were of unique concern. The next objective, proving the viability of SS-MLI, is needed to document its tank applied performance, which has been previously measured in calorimeter tests only. ${ }^{14}$ SS-MLI was used under the broad area cooled shield, maintained at 90K. This creates a warm boundary temperature that is significantly colder than that in previous tests for propellant storage and other MLI. Given the two LH2 tests, one with traditional MLI that used standoffs to support the cooled shield and the second that used the self-supporting MLI to support that shield, the results permitted a direct comparison of the two designs. The last objective, to achieve zero boil-off, was to control the cryocooler cold end temperature such that propellant tank pressure was held constant while the tank was unvented. The robustness of the system was found by adjusting the cryocooler input power to establish a net tank heat leak relationship with tank pressure control.

The sequence of tests was performed as follows:

1) CBRS I, a LH2 test with plastic standoffs supporting the BAC shield and traditionally constructed MLI both under and over the BAC shield

2) CBRS II, a LH2 test with self-supporting MLI (SS-MLI) under the shield (and performing the structural role) and traditional MLI over the shield

3) LOX ZBO test, a tube-on-tank test with the active cooling system used to directly control tank pressure and with traditional MLI on the tank. 


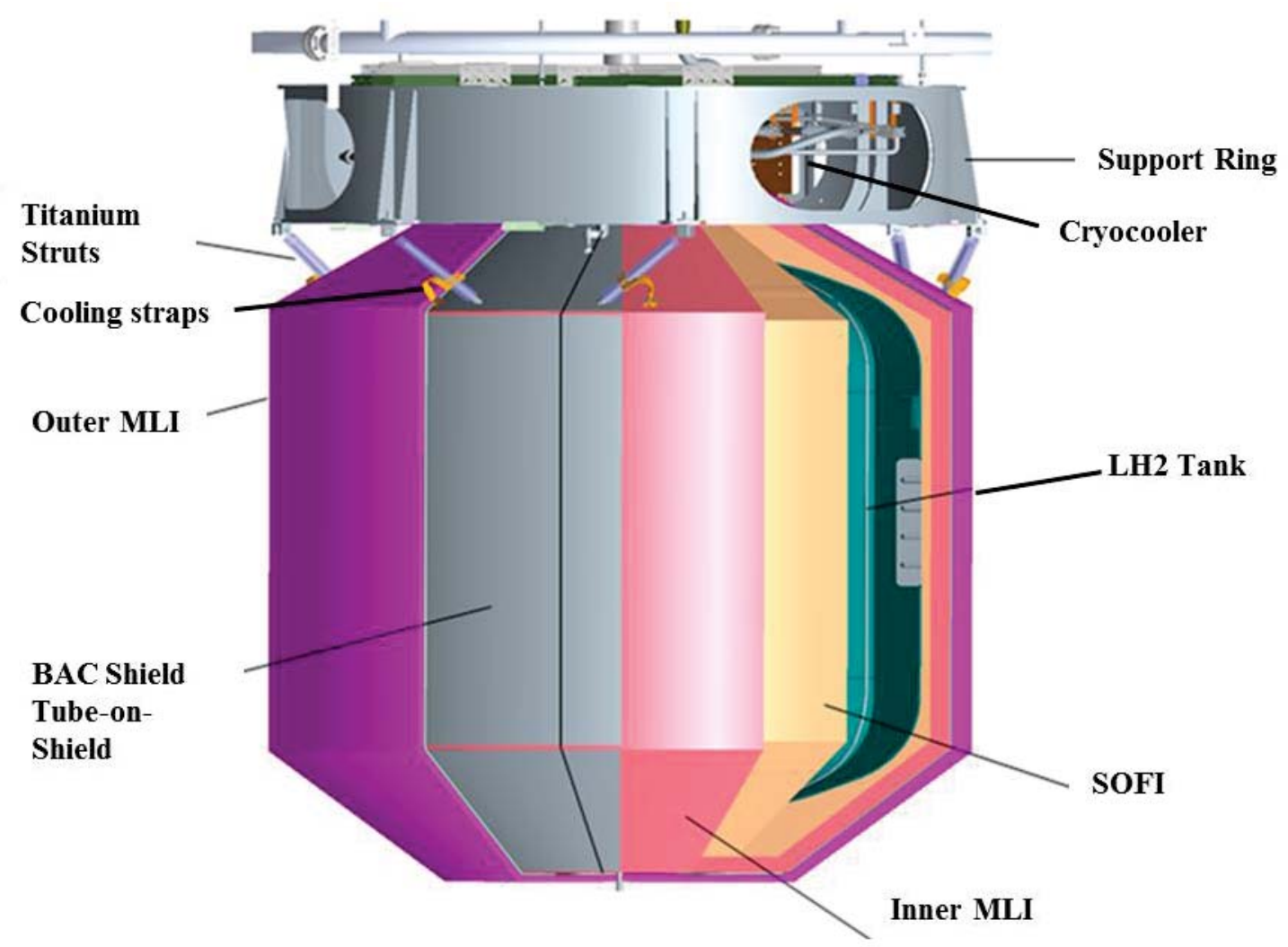

Figure 2. 3-D view of CBRS test article.

\section{Hardware Description}

The test set-up included the facility hardware, propellant tank, support ring, radiator (not shown), broad area cooling (BAC) network including cooling straps, cryocooler, SOFI, inner MLI, and outer MLI (see Figure 2). The facility hardware includes the Small Multi-Purpose Research Facility (SMIRF) vacuum chamber, a $1.8 \mathrm{~m}$ diameter by $2.3 \mathrm{~m}$ long cylindrical chamber that can create and hold a vacuum pressure of $10^{-6}$ torr. Inside the chamber walls is the cryoshroud; this uses cold nitrogen gas to control the background thermal environment at 220K. These two elements provide the LEO environment for the test article. Inside the cryoshroud is the stainless steel test tank, $1.22 \mathrm{~m}$ inside diameter by $1.4 \mathrm{~m}$ tall, with a $0.95 \mathrm{~cm}$ wall and a tank volume of $1.37 \mathrm{~m} 3$. The tank is supported by six tapered titanium struts, with a maximum diameter of $1.9 \mathrm{~cm}$, an average wall thickness of $0.0126 \mathrm{~cm}$, and a length of $0.37 \mathrm{~m}$. The struts are supported by the support ring, which is also used to support the cryocooler assembly and radiator. 
The radiator consists of two curved panels made from 1/8" thick aluminum with four horizontal alumina ammonia heat pipes. A minimum of three temperature sensors were installed at the ends of the radiator panels, and at least four temperature sensors were installed at the midpoint of each panel. At the ends of the radiator panels is the evaporator plate where the cryocooler hot interface is attached. The radiator outer surface was coated with a white paint, Aeroglaze A276, with a measured emissivity of 0.935 . The inner radiator surface was insulated with MLI to limit the heat transfer to the colder surfaces. The assembled unit hanging from the vacuum chamber lid is shown in Figure 3.

\section{A. Active Cooling System}

The CBRS cryocooler with integrated circulator is a $15 \mathrm{~W}$, $90 \mathrm{~K}$ class cryocooler (with integrated circulator) is a reverse turbo Brayton cycle unit. The cryocooler is a modification of the Government-owned Alaska Cryocooler System 2SD two-stage cryocooler. The modifications were (1) elimination of the second-stage turbo-alternator and recuperator; (2) replacement of the commercial compressor inlet filter and aftercooler with updated versions; (3) alteration of the compressor flow passages for lower flow rates; and (4) repackaging the cryocooler assembly and reconfiguring the tubing, valves, and fittings to interface with the NASA distributed cooling network. The fluid in the tubing network is neon, the same fluid as used in the cryocooler system.

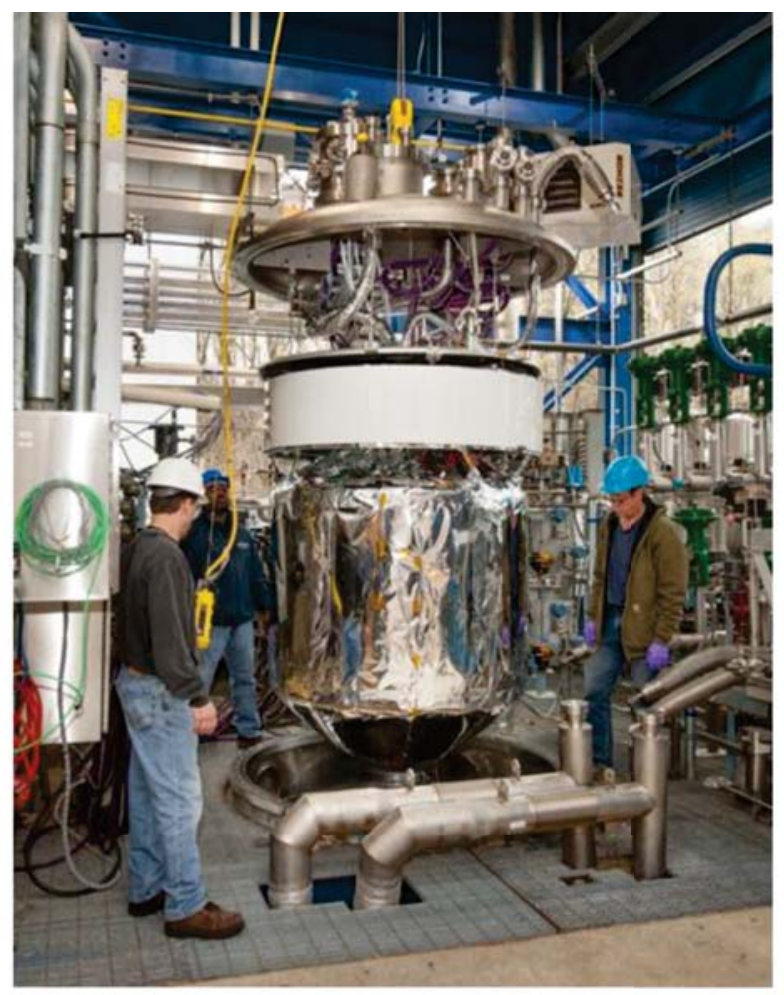

Figure 3. The assembled cryogenic boil-off reduction system test article. 

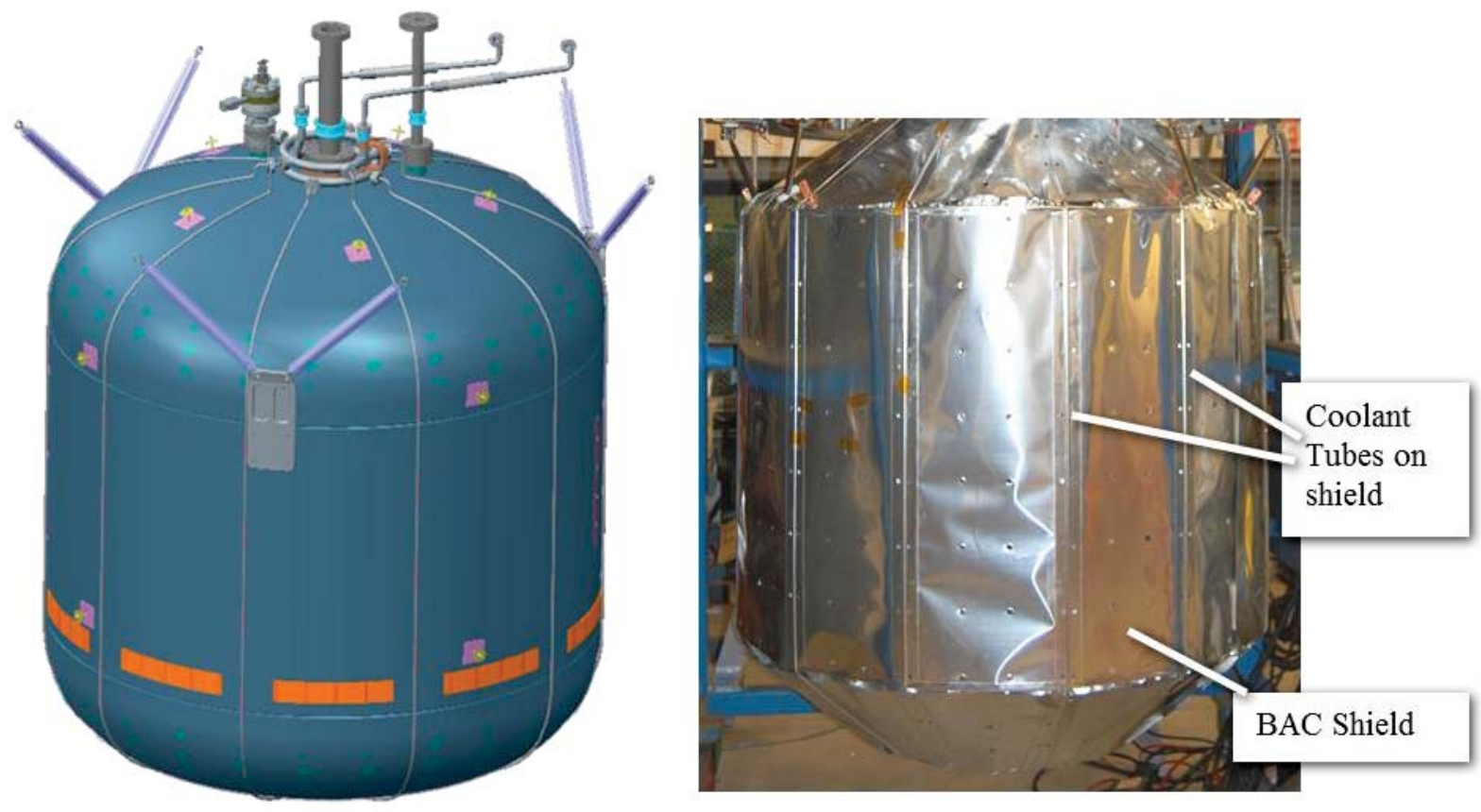

Figure 4. Tube-on-tank on left, tube-on-shield concept on right.

The distributed cooling system consists of $0.063 \mathrm{~cm}$ tubes epoxied and spot welded on the tank for the tube-ontank tests, with 10 cooling tubes, and epoxied on the BAC shield for the tube-on-shield tests, with 12 cooling tubes of the same size. These two configurations are shown in Figure 4.

\section{B. Multi-Layer Insulation}

The design of the MLI was found by analytically changing the number of MLI layers inside and outside of the BAC shield using the Lockheed equations ${ }^{15}$ to estimate performance, finding the cryocooler system and tank boiloff mass, and determining the lowest overall mass solution.

\section{Cryogenic Boil-Off Reduction System Test I}

The cooling system and the tank were insulated with MLI. For the first LH2 test, CBRS I, the inner MLI under the broad area cooling shield consists of 30 layers of double-aluminized Mylar (DAM) with B4A Dacron net bumper strip spacers, to achieve a 10 layer/cm density. The DAM is 0.25 mil thick, with 1000 Angstrom thick aluminum films. For durability, each sub-blanket was wrapped with a 2-mil over-layer. The seams were sewn with Velcro while fully compressed, and oriented vertically to span the length of the tank at three equally spaced intervals to allow for removal and reinstallation of the blanket. To facilitate venting, all DAM layers were perforated; the hole diameter was $0.059 "$ and holes were uniformly spaced to produce a $1 \%$ open area. The inner MLI conformed to the surface of the tank-applied spray on foam insulation (SOFI). The SOFI was included to prevent purge gas liquefaction, as required for on-orbit upper stages. Structural standoffs were epoxied to the tank wall, under the SOFI, to support the broad area cooled shield (BAC). The upper blanket conformed to the geometry of the SOFI and the BAC, which had a cylindrical section around the barrel and truncated conical sections over the domes, as shown in Figure 2. The outer blanket had 30 layers of 0.25 mil thick DAM with two Dacron net spacers per layer. The layer density was 20 layers $/ \mathrm{cm}$. The seams were butted together with every fifth layer taped.

\section{Cryogenic Boil-Off Reduction System Test II}

While the same propellant tank and SOFI were utilized for CBRS II, the MLI and BAC standoffs were removed. The inner MLI was replaced with the SS-MLI blanket, consisting of 18 layers of 1-mil DAM separated by low-conductance spacers. These spacers maintained the layer density of the inner blanket at 5.5 layers $/ \mathrm{cm}$. An edge on view of this MLI is shown in figure 5. No other spacer material (e.g., netting) was used, thereby reducing layerto-layer thermal shorting. The nominal post-to-post spacing was 2 in, and the posts were placed in a stacked grid arrangement. The seams were overlapped by an excess of Mylar width. The inner blankets were shaped to conform 
to the surface of the SOFI and were affixed to SOFI via Velcro strips. On the exterior of the inner MLI, Velcro was applied to couple it with the broad area cooled shield, which had the same Velcro pattern installed on its inside surface. The outer MLI was replaced with the same MLI design as the outer MLI in CBRS I: a 30 layer exterior blanket with a layer density of 20 layers/cm.

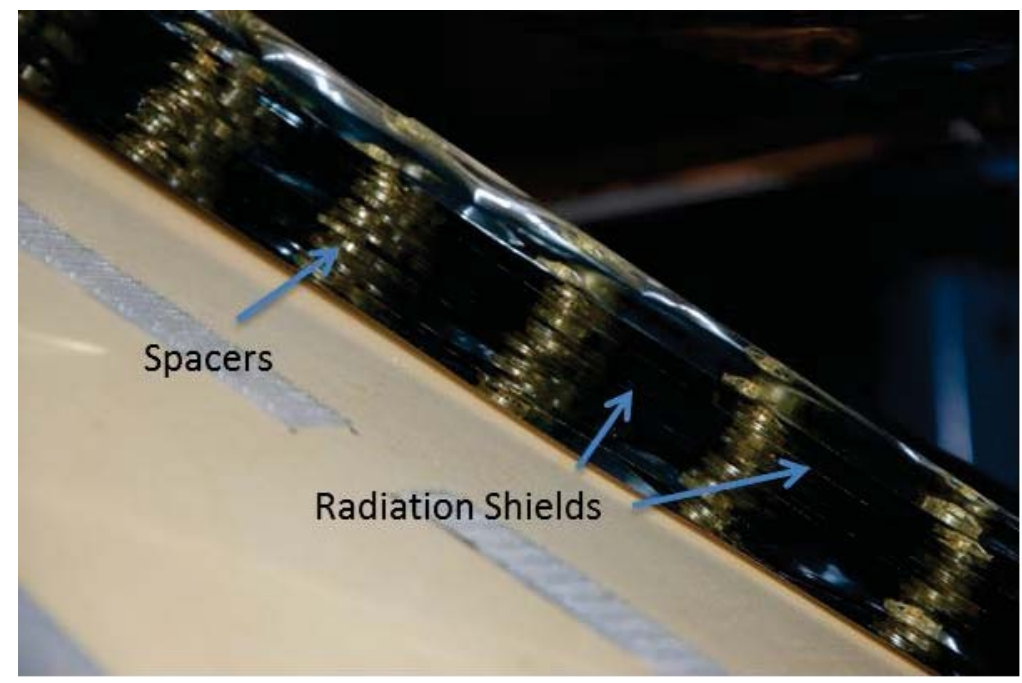

Figure 5. End on view of the SS-MLI.

\section{Zero Boil-Off Test}

The ZBO test article was insulated with 75 layers of MLI, constructed from two 37 layer sub-blankets with each layer again separated by 2 layers of Dacron netting. The layer density was 24 layers $/ \mathrm{cm}$. The blankets were vented through the seams with a $1 \%$ open area in the outer 2-mil cloth reinforced layer of Mylar. Seams were butted together and taped every fifth layer.

A summary of the differences between the CBRS I, II, and ZBO are shown in table 1.

\section{Instrumentation}

The MLI was instrumented to provide a temperature profile through the thickness of the MLI. CBRS I included six temperature sensors through the thickness at six different locations. In CBRS II, there were six temperature sensors through the thickness at four different locations. In the ZBO test, there were nine temperature sensors through the thickness at one location.

Each heat conduction path into the tank was instrumented with redundant temperatures sensors at the hot and cold ends. When coupled with the known geometry between sensors and the material property information, the heat leak along each path was calculated. For the reduced boil-off tests, only one of the six struts was instrumented, while all six were instrumented on the ZBO test. The BAC shield had temperature sensors in 5 locations along each of the flow tubes. It also had sensors between the tubes to measure the temperature difference between the tubing along the shield. The tank wall had temperature sensors at the tank top, bottom, and middle as well as near the tank struts. Inside the tank, eight silicone diodes acted as both temperature sensors and liquid level sensors. In total, there were 49 silicon diodes and 150 thermocouples used in each test. Other sensors used were four flowmeters, to determine the tank boil-off rate, redundant tank pressure transducers, vacuum gauges, and cryoshroud temperature sensors. 
Table 1. Test Configuration Differences.

\begin{tabular}{|c|c|c|c|}
\hline 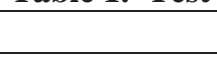 & CBRS I & CBRS II & ZBO \\
\hline MLI & $\begin{array}{l}30 \text { layers of } 10 \text { layer/cm } \\
\text { traditional MLI under } \\
\text { shield, } 30 \text { layers of } 20 \\
\text { layers/cm traditional MLI } \\
\text { over shield. }\end{array}$ & $\begin{array}{l}18 \text { layers of } 5.5 \text { layer } / \mathrm{cm} \\
\text { SS-MLI under shield, } 30 \\
\text { layers of } 20 \text { layer/cm } \\
\text { traditional MLI over } \\
\text { shield. }\end{array}$ & $\begin{array}{l}75 \text { layers of traditional } \\
\text { MLI with } 24 \text { layer/cm } \\
\text { density. }\end{array}$ \\
\hline BAC & $\begin{array}{l}\text { Tube-on-shield, } 12 \text { tubes } \\
6.4 \mathrm{~mm} \text { dia. } \\
\text { epoxied to } 5 \mathrm{mil} \text { Al } 1235 \\
\text { sheet. }\end{array}$ & Same as CBRS I. & $\begin{array}{l}\text { Tube-on-tank, } 10 \text { tubes } 6.4 \\
\text { mm dia. }\end{array}$ \\
\hline BAC Support & $\begin{array}{l}\text { Supported at tank } \\
\text { penetrations and with } 12 \\
\text { Ultem standoffs epoxied to } \\
\text { tank wall. }\end{array}$ & $\begin{array}{l}\text { Supported off of the inner } \\
\text { MLI by Velcro epoxied to } \\
\text { inner surface of shield and } \\
\text { mated to Velcro on outer } \\
\text { surface of inner-MLI }\end{array}$ & $\begin{array}{l}\text { Tubes were epoxied and } \\
\text { spot welded to the } \\
\text { propellant tank }\end{array}$ \\
\hline Cooling straps & $\begin{array}{l}\text { Vent and fill line straps, } \\
\text { tank support strut straps on } \\
\text { all six struts. }\end{array}$ & $\begin{array}{l}\text { Fill line and tank support } \\
\text { straps. Improved coupling } \\
\text { of straps, particularly on } \\
\text { fill line. }\end{array}$ & $\begin{array}{l}\text { Vent line cooling strap } \\
\text { only. }\end{array}$ \\
\hline
\end{tabular}

\section{Testing}

Table 2 discusses the various tests conducted during the duration of the test series. These tests were conducted with the vacuum of $1 \times 10-6$ torr or better and the cryoshroud was set at $220 \mathrm{~K}$, providing the space vacuum and thermal environment needed for LEO simulation. The tank liquid level was nominally at $90 \%$ full for all tests. The CBRS $\mathrm{LH}_{2}$ tests were all performed at a storage pressure of 25 psia, a nominal pressure for pump-fed engines, while the $\mathrm{ZBO}$ tests were performed with $\mathrm{LN}_{2}$ as the $\mathrm{LO}_{2}$ surrogate at 82 psia. At this condition, the $\mathrm{LN}_{2}$ is at a saturation temperature of $95.5 \mathrm{~K}$, which is the same saturation temperature as $\mathrm{LO}_{2}$ at 25 psia.

The tests listed in Table 2 are discussed herein:

Table 2. Test Matrix and Associated Goal.

\begin{tabular}{|l|l|}
\hline Test & Purpose \\
\hline CBRS I Cooler Off & Establish tank boil-off rate and heat leak \\
\hline CBRS I Cooler On & Determine active cooling system performance \\
\hline CBRS II Cooler Off & Establish tank boil-off rate and heat leak \\
\hline CBRS II Cooler On & Determine active cooling system performance \\
\hline ZBO Cooler Off & Establish tank boil-off rate and heat leak \\
\hline ZBO Cooler On & Control tank pressure and determine active cooling system performance \\
\hline ZBO High Power & Determine robustness of cryocooler system \\
\hline ZBO Low Fill Level & Control tank pressure and determine active cooling system performance at low fill level \\
\hline
\end{tabular}

\section{A. Pre-Test Model}

For each of the three tests, CBRS I and II and ZBO, a Thermal Desktop model was created. This model predicted the heat leak for each component with the cooler off, the reduced boil-off with the cooler on, and the total heat leak for each test, as shown in Table 3. The cryocooler was bench tested at the vendor site, establishing its baseline performance at 4 different cryocooler lifts, each at 3 different heat rejection temperatures, so a model of its performance was not required. 
Table 3. Pre-Test Heat Leak Model.

\begin{tabular}{|l|l|ll|l|}
\hline & $\begin{array}{l}\text { CBRS } \\
\text { (W) }\end{array}$ & $\begin{array}{l}\text { CBRS II } \\
\text { (W) }\end{array}$ & $\begin{array}{l}\text { ZBO } \\
\text { (W) }\end{array}$ \\
\hline Cooler Off & 3.7 & 3.2 & 5.1 \\
\hline $\begin{array}{l}\text { Cooler On } \\
\text { Boil-Off } \\
\text { Reduction, } \\
\text { BOR }\end{array}$ & 1.9 & 1.3 & 0 \\
\hline
\end{tabular}

\section{B. Test Results}

\section{Cryogenic Boil-Off Reduction System Test I}

The first CBRS test had a tank heat leak of $3.9 \mathrm{~W}$ with the cryocooler off and a heat leak of $2 \mathrm{~W}$ with the cryocooler on (see Table 4). Note that the measured heat leaks were higher, but an adjustment was made to compensate for the Thermo-Acoustic Oscillation heat leak measured in CBRS II, which was assumed to be the same as CBRS I. The resultant boil-off rate reduction was $48 \%$, which was close to the model prediction. Two components performed worse than expected - the radiator and the inner MLI. It was found that the radiator was improperly oriented during assembly, preventing the heat pipe from operating as designed and causing the cryocooler to operate warmer than planned, limiting its performance. The inner MLI heat leak, $0.79 \mathrm{~W}$ through the 30 layers, was significantly more than the $0.38 \mathrm{~W}$ in the model. The top and bottom sections of the inner MLI had all of the structural standoffs of the cooled shield penetrating it. Another aspect of the test that affected the boil-off reduction was the vent line cooling strap. The vent line was continuously cooled by the hydrogen vapor, creating a heat leak that was lower than expected. This reduced the usefulness of the cooling strap so it was removed for the second test.

The cooling strap performance was as expected on the tank strut straps, but less than expected for the fill line. The tank strut heat was reduced by $62 \%$ while the fill line heat was only reduced $50 \%$. Post-test inspection found that the strap was improperly clamped on the fill line, degrading its conductance.

\section{Cryogenic Boil-Off Reduction System Test II}

The second reduced boil-off test, using the self-supporting MLI under the BAC shield, had a tank heat leak of $3.3 \mathrm{~W}$ with the cryocooler off and a heat leak of $1.8 \mathrm{~W}$ with the cryocooler operating at a heat removal rate of removing $10.7 \mathrm{~W}$ of heat (Table 4). The boil-off reduction was $45 \%$, slightly less than that in the CBRS I. The inner MLI heat leak was $0.65 \mathrm{~W}$, down from $0.79 \mathrm{~W}$ in the first test, an $18 \%$ reduction. Due to changes made in insulating the tubing between the shield and the cryocooler, the cryocooler lift requirement for CBRS II dropped from 13.2 W to 10.6 W. Note that, in addition to changing the inner MLI, other changes were made to CBRS II. The attachment of the cooling straps was enhanced with the use of larger, stronger washers to better secure their coupling. Also, the fill line cooling clamp was reinstalled per its design. Thus, the strut cooling straps removed 68\% of the strut heat, while the fill line strap removed $64 \%$ of that the fill line heat, both improvements from CBRS I. Additionally, the radiator performed much better than in the first test, as an alignment problem was fixed, reducing its thermal gradient substantially and allowing the cryocooler to operate near its nominal temperature of $300 \mathrm{~K}$.

The inner MLI heat leak reduction is attributed to the performance of the self-supporting MLI, which similarly performed better than traditional MLI in calorimeter coupon tests. ${ }^{14}$ Yet both inner MLI's had higher heat leak than the pre-test NASA model. A post-test study of the MLI temperature profile and the predictive equations reveals that the temperature dependency as suggested in the Lockheed equation was not realized in this MLI at this temperature region-between 20 and 90K. Because the Lockheed equation was used in the BAC shield locator design, it is likely that the shield was not located optimally.

While these components improved in CBRS II, the uncooled vent line had the same heat as CBRS I for the Cooler On test. The Cooler Off vent line heat dropped from .09 to $0.046 \mathrm{~W}$, a substantial drop that shows that the cooling strap was warming the tank in the first test. Future designs for this strap must consider the vent flow rate chilling aspect in the cooling strap positioning on the vent line, for optimization.

Besides the vent line, the capacitance probe, instrumentation, and instrumentation port were also not cooled. The sum of these is shown in the non-cooled heat row of Table 4. While these were all small heat leaks as expected, each contributes to the tank boil-off and could have been coupled to a cooling strap. If they were cooled similarly to 
the fill line and struts, the overall boil-off reduction would have increased to $55 \%$, and the vent and penetration integration heat leak would have been the only uncooled elements.

Table 4. Test Data.

\begin{tabular}{|c|c|c|c|c|c|c|c|c|}
\hline & \multicolumn{3}{|c|}{ CBRS I } & \multicolumn{3}{|c|}{ CBRS II } & \multicolumn{2}{|c|}{ ZBO } \\
\hline & Cooler Off & Cooler On & $\begin{array}{l}\text { Heat or Boil- } \\
\text { Off (\%) } \\
\text { Reduction }\end{array}$ & Cooler Off & Cooler On & $\begin{array}{l}\text { Heat or Boil- } \\
\text { Off (\%) } \\
\text { Reduction }\end{array}$ & Cooler Off & Cooler On \\
\hline BO* & 3.87 & 2.03 & $48 \%$ & 3.32 & 1.83 & $45 \%$ & 4.3 & 0 \\
\hline MLI & 2.04 & 0.79 & $61 \%$ & 1.46 & 0.65 & $55 \%$ & 2.62 & 2.62 \\
\hline Vent & 0.09 & 0.11 & $-22 \%$ & 0.046 & 0.11 & $-139 \%$ & 0.14 & 1.43 \\
\hline Fill & 0.38 & 0.19 & $50 \%$ & 0.5 & 0.18 & $64 \%$ & 0.49 & 0.51 \\
\hline Struts & 0.604 & 0.23 & $62 \%$ & 0.63 & 0.2 & $68 \%$ & 0.38 & 0.40 \\
\hline $\begin{array}{c}\text { Capacitance } \\
\text { Probe }\end{array}$ & 0.21 & 0.21 & $0 \%$ & 0.21 & 0.22 & $-5 \%$ & 0.006 & 0.006 \\
\hline $\begin{array}{l}\text { Penetration } \\
\text { Integration }\end{array}$ & 0.34 & 0.34 & $0 \%$ & 0.17 & 0.17 & $0 \%$ & 0 & 0 \\
\hline Standoffs & 0.12 & 0.05 & $58 \%$ & 0 & 0 & $0 \%$ & 0 & 0 \\
\hline Instrumentaion & 0.1 & 0.1 & $0 \%$ & 0.17 & 0.17 & $0 \%$ & 0.07 & 0.06 \\
\hline Instr. port & & & & 0.13 & 0.13 & $0 \%$ & & \\
\hline non-cooled heat & 0.65 & 0.65 & $0 \%$ & 0.596 & 0.67 & $-12 \%$ & & \\
\hline Cooled items & 3.114 & 1.32 & $58 \%$ & 2.59 & 1.03 & $60 \%$ & & \\
\hline & & & & 3.186 & 1.7 & & & \\
\hline & & hermal acou & ustic oscillation & leat remove & & & & \\
\hline Q lift & & 13.2 & & & 10.7 & & & 8.5 \\
\hline Q BAC & & 5.84 & & & 5.23 & & & 4.52 \\
\hline Qstruts & & 1.21 & & & 2.09 & & & 0.48 \\
\hline Q parasitic & & 6.17 & & & 3.34 & & & 4.2 \\
\hline Q compressor & & 245 & & & 223 & & & 145 \\
\hline
\end{tabular}




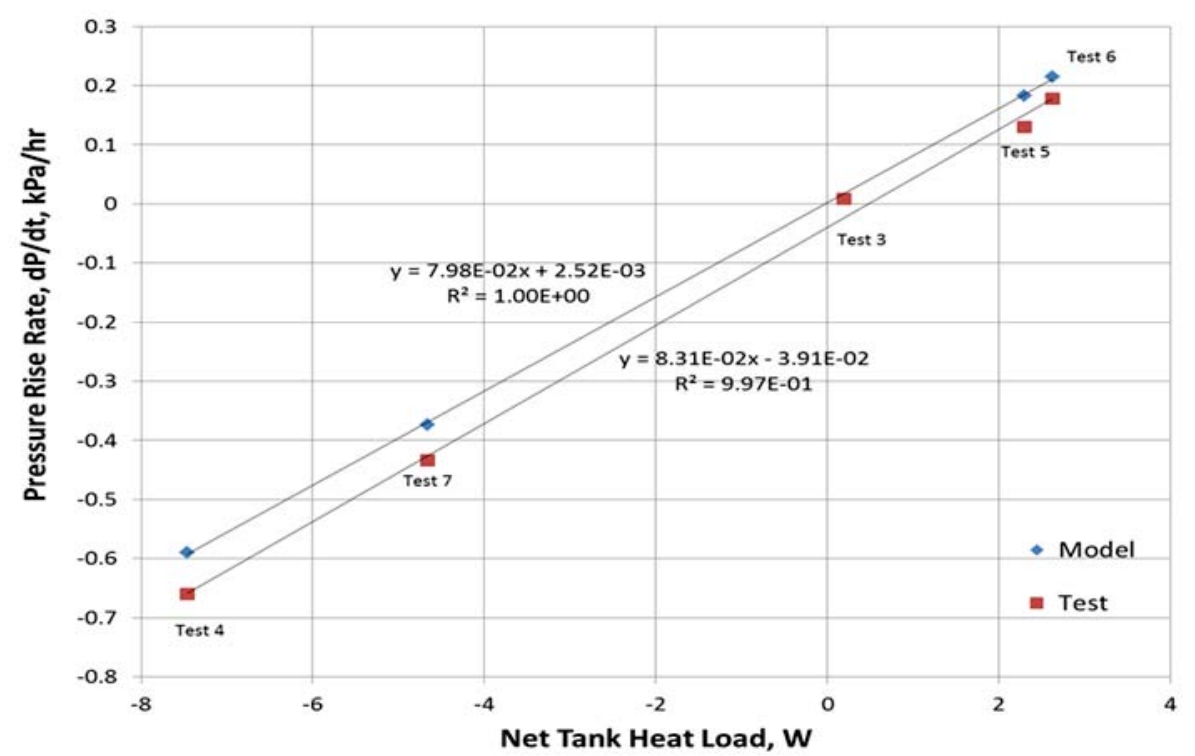

Figure 6. ZBO tank pressurization rates vs. net tank heat.

\section{Zero Boil-Off Test}

The zero boil-off test had a cooler-off steady state heat leak of $4.3 \mathrm{~W}$. With the cryocooler on, the cooling tube network dropped the tank lid temperature $6.5 \mathrm{~K}$ and dropped the ullage temperature by $2.2 \mathrm{~K}$. Zero boil-off was achieved with a cryocooler lift of $8.5 \mathrm{~W}$ and an input power of $145 \mathrm{~W}$. Follow-on cryocooler testing with the cryocooler input power at $212 \mathrm{~W}$, a $1 / 3^{\text {rd }}$ increase in power, was effective at dropping the tank pressure by 0.067 $\mathrm{psi} / \mathrm{hr}$ over a 22-hour period. This depressurization rate was consistent with that predicted by an isothermal fluid model, showing that the propellant behavior is consistent with that of unstratified fluid. This shows that the tank pressure response was consistent with a tank propellant that has minimal thermal stratification, suggesting that there is no need for an internal tank mixer operation in conjunction with the cryocooler operation. Additional tests at varying cryocooler input power levels were conducted and the associated net heat into or out of the tank were plotted as shown in Figure 6, along with the model predictions. Another test was conducted at a low fill level, a likely condition for propellant depot applications. The low fill level state (at approximately $25 \%$ full) is associated with higher fluid stratification, causing a warmer tank lid and higher tank pressures. In this test, at the same input power as the full tank ZBO test, the cryocooler removed all the tank heat and the system achieved ZBO.

The cryocooler system unusable lift, the parasitic loss associated with cryocooler integration with propellant tanks, was $4.2 \mathrm{~W}$, higher than the $3.3 \mathrm{~W}$ in CBRS II but lower than the $6.2 \mathrm{~W}$ in CBRS I. A post-test dissection of the ZBO test MLI points to the use of a high emissivity tape (that looked like a low emissivity tape) on the distribution manifold as the primary source of this heat. Using tubing insulation performance data relationships generated at KSC, a properly insulated manifold and associated tubing would have cut the parasitics to $1.5 \mathrm{~W}$, a more reasonable portion of the total cryocooler lift (18\%).

Although the parasitic loss was higher than expected, the flow and thermal losses of the cryocooler's neon loop were lower than expected. The BAC thermal gradient from tank top to bottom for all three tests was an average of $2.5 \mathrm{~K}$, beating the design goal of $5 \mathrm{~K}$. The neon loop pressure drop was 0.3 psid, lower than the goal of 0.6 psid.

The MLI heat leak for the 75 layers of traditional MLI was 2.6 W. Again, the MLI layer temperatures nearest the colder tank surface did not correlate well with prediction, similar to the inner MLI on the LH2 tank even though these layers were a bit warmer.

\section{Scaling Study Validation}

The ZBO results along with the CBRS test data was checked with the cryogenic analysis tool used in the Scaling Study. The test results were used to provide several corrections for the cryocooler scaling performance in the model in order to provide more accurate predictions of cryocooler performance. 
The main updates made to the model based on this test series include:

1) MLI equations updated based on test data results

2) Cooling strap effectiveness to accommodate the actual thermal losses encountered in testing

3) Updated radiator sizing, with the inclusion of the actual radiator temperature due to the thermal losses in the integration plate that mounts the cryocooler compressor to the radiator.

4) Addition of the parasitic heat leak for the cryocooler due to the heat entering the tubing between the BAC manifolds and the cryocooler

With the new updates to the model, the active control system mass increased slightly, shifting the resultant "equal mass" duration from 7.3 days to 8.0 days, a $10 \%$ increase, as shown in Figure 7 . This "equal mass" is the duration point in LEO where the passive thermal control system mass and the active thermal control system mass are equal. At durations longer than this, active cooling reduces the total integrated system mass and should be considered in the mission architecture. Not yet understood in the scaling study update is the MLI boil-off reduction, which was reduced by roughly $60 \%$ in the tests, less than expected. This could be related to the relatively poor inner MLI performance at low temperatures.

\section{Conclusions}

The integration of the reverse turbo-Brayton cycle cryocooler into a propellant tank proved to be feasible for NASA mission architecture concepts that require long loiter periods in space. Both reduced boil-off and zero boil-off applications were demonstrated on a 1.2 meter diameter tank. Tank boil-off was reduced by $48 \%$ in the first test and $45 \%$ in the second test. The boil-off reduction would have been higher if the other small heat leak sources were also cooled and if the vent line cooling strap was located optimally. Where the cooling straps were used, the boil-off was reduced by 2/3rds. Also, the BAC shield reduced the MLI heat by 55-60\%, somewhat less than expected. The MLI that was under the cooled shield for both self-supporting and traditional MLI performed below anticipated levels. Because the data shows a breakdown in the Lockheed equation in the 20-90 K temperature range, more MLI and shield design and testing is required to remove more heat. Despite that, where cooling was utilized tank heat and boil-off was reduced by $60 \%$.

\section{Thermal system mass comparison for a $182.6 \mathrm{~m} 3$ LOX tank with 75 layers of traditional MLI ( DF $=2$ ) and a tank heat leak of $318 \mathrm{~W}$}

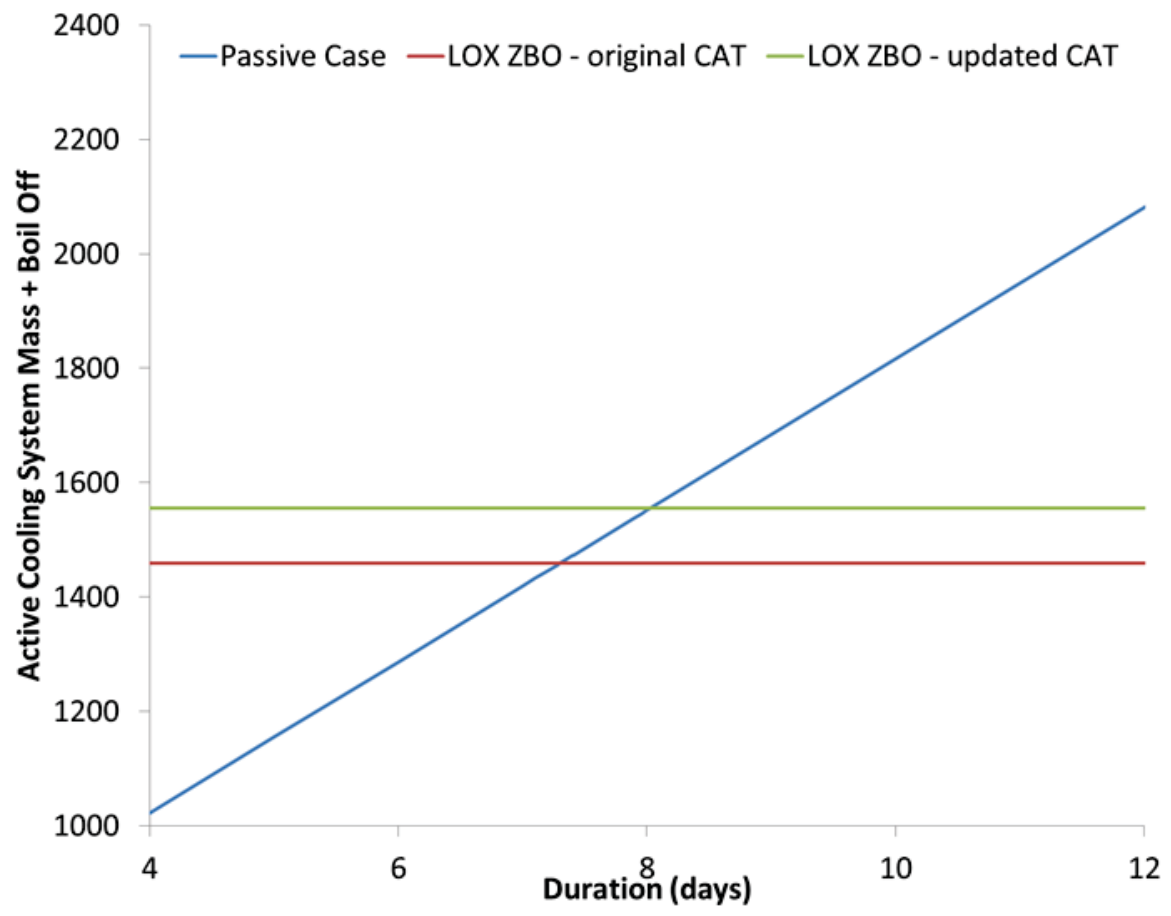

Figure 7. Thermal mass vs. duration. 
The use of self-supporting MLI was very successful. It reduced the heat leak into the tank by $18 \%$ and eliminated the use of the broad area cooled shield structural standoffs, another source of tank heat.

The tube-on-tank zero boil-off application was also successful. In this test, the cryocooler system was used to effectively control tank pressure. In addition, robust tank pressure control was demonstrated. It was found that the cryocooler distributed cooling network greatly suppressed propellant stratification, potentially negating the need for an internal tank mixer when the cryocooler is operational. In addition, the cooling network's heat transfer and flow losses were small, and although the parasitics were higher than expected an improved insulation design would have greatly reduced the parasitic loss.

Finally, the test data was used to modify the cryogenic boil-off reduction system model, which was re-run to evaluate the projected performance in the Scaling Study. While these results changed slightly, the scaling study results for the ZBO case were validated. In the reduced boil-off case, the cooling strap performance was validated but the low temperature inner MLI under-performance and reduced boil-off reduction requires further development.

\section{Acknowledgments}

The authors would like to acknowledge the design team led by Robert Christie at Glenn Research Center, the SOFI, BAC, and MLI fabricators at Marshall Space Flight Center, the tube-on-tank and ZBO MLI fabricators at Sierra Lobo, and the facility team at Glenn Research Center, led by Craig Robinson. Funding was provided by both the Cryogenic Propellant Storage and Transfer Technology Demonstration Mission and the Self-Supporting Multilayer Insulation Project within the Game Changing Technology Division of the Space Technology Mission Directorate.

\section{References}

1 "National Space Policy of the United States of America," URL:

http://www.whitehouse.gov/sites/default/files/national_space_policy_6-28-10.pdf

2 Rey, K., et. al., “Ares V: Application to Solar System Scientific Exploration,” JPL publication 08-3, 2008. URL: http:/hdl.handle.net/2014/40727

3 “'Space Launch System,” NASA Facts, 2012, URL: http://www.nasa.gov/pdf/664158main_sls_fs_master.pdf

${ }^{4}$ M.G. Houts, et. al., "Nuclear Cryogenic Propulsion Stage," Nuclear and Emerging Technologies for Space (2012), URL:

http://www.lpi.usra.edu/meetings/nets2012/pdf/3093.pdf

${ }^{5}$ D. Arney, A. Wilhite, “Orbital Propellant Depots Enabling Lunar Architectures Without Heavy-Lift Launch Vehicles,” Journal of Spacecraft and Rockets, Vol. 47, No. 2, March-April 2010

${ }^{6}$ Hoffman, S., Drake, B., Baker, J., and Voels, S., "Mars As a Destination in a Capability-Driven Framework," Proceedings of Earth and Space 2012: pp. 1505-1514, American Society of Civil Engineers.

${ }^{7}$ Augustine, N.R. (2009). "Summary report of the review of U.S. human space flight plans committee," URL: http://www.nasa.gov/offices/hsf/related_documents/summary_report.html (July 14, 2012).

${ }^{8}$ J.R.Feller, D.W.Plachta, et. al., "Demonstration of a Cryogenic Boil-Off Reduction System Employing an Actively Cooled Thermal Radiation Shield," Cryocoolers 16, (International Cryocooler Conference, 2010).

${ }^{9}$ D. Plachta, "Results of An Advanced Development Zero Boil-Off Cryogenic Propellant Storage Test,” NASA TM $2004-$ 213390.

${ }^{10}$ M. Zagarola, et.al., "High-Capacity turbo-Brayton Cryocoolers for Space Applications.” Cryogenics 46 (2006): 169-175.

${ }^{11}$ Dye SA et al., "Design, Fabrication and Test of Load Bearing Multilayer Insulation To Support a Broad Area Cooled Shield," Cryogenics (2014), URL: http://dx.doi.org/10.1016/j.cryogenics.2014.06.001

${ }^{12}$ Johnson, W.L., Valenzuela, J.G., et., al., “Tank Applied Testing of Load Bearing Multi-layer Insulation,” presented at the 2014 AIAA Propulsion and Energy Conference, Cleveland, OH, July 28-30, 2014

${ }^{13}$ Plachta, D, Guzik, M., “Cryogenic Boil-Off Reduction System Scaling Study,” Cryogenics Volume 60, pages 62-67, 2014,

URL: www.elsevier.com/locate/cryogenics 
${ }^{14}$ Johnson, W. L., et. al., “Thermal Coupon Testing of Load Bearing Multi-layer Insulation,” Advances in Cryogenic Engineering, Vol. 59A, American Institute of Physics Conference Proceedings 1573, Melville, NY, 2014, pg. 175.

${ }^{15}$ NASA CR-134477, Keller, C. W., Cunnington, G. R., and Glassford, A. P., Thermal Performance of Multilayer Insulations, Lockheed Missiles \& Space Company, April 1974. 